\title{
BMJ Open Multiple sclerosis course and clinical outcomes in patients with comorbid asthma: a survey study
}

\author{
Ali Manouchehrinia, ${ }^{1,2}$ Laura J Edwards, ${ }^{1}$ Homayoun Roshanisefat, ${ }^{3,4}$ \\ Christopher R Tench, ${ }^{1}$ Cris S Constantinescu ${ }^{1}$
}

To cite: Manouchehrinia A, Edwards LJ, Roshanisefat $\mathrm{H}$, et al. Multiple sclerosis course and clinical outcomes in patients with comorbid asthma: a survey study. BMJ Open 2015;5:e007806. doi:10.1136/bmjopen-2015007806

- Prepublication history for this paper is available online To view these files please visit the journal online (http://dx.doi.org/10.1136/ bmjopen-2015-007806).

Received 28 January 2015 Revised 13 April 2015 Accepted 15 April 2015

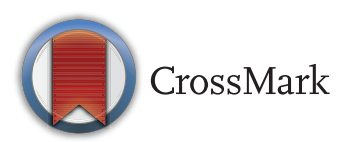

${ }^{1}$ Division of Clinical Neuroscience, Clinical Neurology Research Group, University of Nottingham, Queen's Medical Centre, Nottingham, UK ${ }^{2}$ Department of Clinical Neuroscience, Karolinska Institute, Stockholm, Sweden ${ }^{3}$ Department of Clinical Neuroscience, CMM; Karolinska Institute, Stockholm, Sweden ${ }^{4}$ Department of Neurology, Karolinska University Hospital Huddinge, Stockholm, Sweden

Correspondence to Professor Cris S Constantinescu; cris.constantinescu@ nottingham.ac.uk

\section{ABSTRACT}

Objective: To determine if comorbid asthma is associated with accumulation of multiple sclerosis (MS)-related impairment and disability.

Method: We sent a comprehensive questionnaire to a cohort of patients with MS and examined the association between comorbid asthma and reaching Expanded Disability Status Scale (EDSS) scores 4.0 and 6.0. Multiple Sclerosis Impact Scale (MSIS-29) scores were compared between patients with MS with and without comorbid asthma.

Results: 680 patients participated in our study of whom $88(12.9 \%)$ had comorbid asthma. There was no difference in the prevalence of asthma between our MS cohort and the England general population (OR: $0.89,95 \% \mathrm{Cl} 0.68$ to 1.17). We did not observe a significant association between having asthma and the risk of reaching EDSS scores 4.0 and 6.0 (HR: 1.29, $95 \% \mathrm{Cl} 0.93$ to 1.77 , and HR: $1.33,95 \% \mathrm{Cl} 0.93$ to 1.89 , respectively) after controlling for confounders. Patients with MS with asthma reported higher level of psychological impairments (coefficient: $2.29,95 \% \mathrm{Cl}$ 0.1 to 4.49).

Conclusions: Asthma is a prevalent condition among patients with MS and it may contribute to the psychological impairment in MS. Although we did not observe significant association between comorbid asthma and physical disability in MS, it seems that the two conditions influence one another.

\section{INTRODUCTION}

Several studies report on various aspects of coexisting asthma and multiple sclerosis (MS); however, the results are contradictory. Traditionally, it was argued that the two conditions are mutually exclusive: asthma is mediated by T helper cells 2 (Th2) and MS by Th1 cells. In 2004, an epidemiological study from our centre found an increased prevalence of asthma and all atopy in patients with MS compared with the general population. ${ }^{1}$ In contrast, a study by Bergamaschi et $a l^{2}$ and another by Tremlett and colleagues showed an inverse association

\section{Strengths and limitations of this study}

- This is the first study investigating the association between comorbid asthma and the progression of impairment and disability in multiple sclerosis (MS).

- The data used in this study was from a wellestablished cohort of patients with MS with detailed and robust disability outcomes.

- Our study has a response rate of $54 \%$. A potential selection bias may result from the proportion of non-responders.

- The asthma in our study is self-reported (although this needed to be confirmed by a doctor).

between asthma and MS. However, these studies had lower numbers of study subjects. ${ }^{3}$ A systematic review and meta-analysis by Monteiro et at has shown no evidence of an association between asthma and MS. On the other hand, it has been shown that patients with MS in general bear a higher risk of immune-mediated diseases. ${ }^{5-7}$ Apart from the speculations on biological plausibility ${ }^{8}$ and the underlying mechanisms, the effect of asthma on the clinical course and prognosis of MS has not been well understood.

In this cohort study, we compared the general and clinical characteristics of patients with MS with and without asthma, and investigated the association between comorbid asthma and physical disability and psychological impairment in patients with MS.

\section{METHOD}

We analysed data from patients registered in the Nottingham University Hospital MS clinics. These clinics are major catchment and referral centres in East Midlands, UK. The centre and patient population has been described in more detail elsewhere. ${ }^{9}{ }^{10}$ In 2013, an asthma and smoking questionnaire with questions obtained from Health Survey 
for England 2010, Respiratory Health (NS) ${ }^{11}$ and European Community Respiratory Health Survey II (ECRHS) $^{12}$ were sent to 1260 patients with a definite diagnosis of MS. Patients were eligible to participate in the research if they were over 18 years of age and had been diagnosed with clinically definite MS by a neurologist according to the McDonald and/or Poser criteria. ${ }^{13}{ }^{14}$ Patients were specifically asked if they had any history of asthma and if so, whether this diagnosis had been confirmed by their general practitioner (GP) or any another relevant physician.

\section{OUTCOMES}

Through the survey, detailed data regarding any history of asthma, individual smoking status, parental smoking during subjects' childhood and place of living before the age of 5 years were obtained. The level of physical and psychological disability were assessed by the Multiple Sclerosis Impact Scale 29 (MSIS-29), data for which were obtained through the questionnaire.

Data with regard to gender, age, age at the onset of MS, duration of disease modifying treatments (DMTs), initial clinical course of MS (relapse onset vs progressive onset MS), and level of disability due to MS as measured by Expanded Disability Status Scale $(\text { EDSS })^{15}$ were obtained from the clinical database held in the Division. The clinical database contained an average of four EDSS scores per patient that were estimated by a neurologist during patients' routine clinic visits.

The study was approved by the National Research Ethics Service East Midlands Ethics Committee Derby-1.

\section{STATISTICAL ANALYSIS}

Descriptive statistics were used to categorise the data. Where appropriate, parametric or non-parametric twosided tests were employed to test the differences between groups, and $\chi^{2}$ test was used to examine the differences between categorical variables.

\section{Association between asthma and MS}

Conditional logistic regression models were used to estimate the likelihood of having asthma in patients with MS compared to the two age and sex matched controls in England's general population.

\section{Risk measurement}

We employed Cox proportional hazard regression models to investigate the differences in the risk of reaching two EDSS score milestones: 4.0 (walking more than $500 \mathrm{~m}$ unaided but having moderate disability) and 6.0 (can walk $100 \mathrm{~m}$ with or without assistance). The HRs were reported as unadjusted and adjusted. Models were adjusted for MS onset age, sex, pack years cigarette smoked, initial clinical course of MS and exposure to DMT. Follow-up time was started at disease onset and ended at the time when EDSS reached the score 4.0 or 6.0 or date of last EDSS (if less than 4 or 6), whichever occurred first; if none of those, it ended on 31 December 2013.

Median regression models were used to investigate the association between MSIS-29 physical and psychological scales in patients with and without asthma. The models were adjusted for MS onset age, sex, initial clinical course of MS, exposure to DMT and disease duration. Only significant covariates were fitted in the final model.

All statistical analyses were performed with Stata V.13.1 (StataCorp. 2013. Stata Statistical Software: Release 13. College Station, Texas, USA: StataCorp LP)

\section{RESULTS}

By March 2013, 680 questionnaires had been returned by subjects who met our inclusion criteria, giving a response rate of $54 \%$. Mean age of respondents was 53 $(\mathrm{SD} \pm 11.33)$ years with a 2:1 female:male ratio. In the patients with MS group, $57 \%$ had relapsing remitting MS (RR MS), 33\% secondary progressive MS (SP MS), and $10 \%$ primary progressive MS (PP MS). Mean MS duration was $19(\mathrm{SD} \pm 10.4)$ years and $54 \%$ were exposed to at least 1-year of disease modifying treatments (DMTs; table 1).

\section{Characteristics of asthma in patients with MS}

In our survey, $12.94 \%(\mathrm{n}=88)$ of the patients reported a history of asthma, which had been confirmed by their GPs. When age-matched and sex-matched controls without MS (from health survey England 2010) were individually assigned to each MS case, we did not observe any association between occurrence of MS and asthma (OR: 0.89, 95\% CI 0.68 to $1.17, \mathrm{p}=0.42$ ). Adjustment of the model for smoking status (eversmoked vs never-smoked) and for parental smoking did not change the risk of developing asthma in patients with MS (OR: $0.92,95 \%$ CI 0.70 to $1.23 p=0.60$; detailed analysis not shown).

Median age at the onset of asthma was 14 (range from 2 to 74 ) years and this onset was 5 years $(95 \%$ CI 3 to 8 , $\mathrm{p}<0.001)$ later in people with MS compared with controls without MS. Twenty eight per cent of patients with MS with asthma reported having an attack of asthma in the past 12 months; however, they were $40 \%$ less likely to have an attack compared with the controls without MS when controlled for age and sex (OR: $0.60,95 \%$ CI 0.37 to $0.98, \mathrm{p}=0.04$ ).

Among patients with MS with asthma, 84\% and 86\% had their first attack of asthma before MS onset and diagnosis, respectively. Of these patients, $15.2 \%$ reported a history of asthma in their fathers and $19.7 \%$ in their mothers; $45.8 \%$ were receiving treatment for their asthma. Overall, $66.6 \%$ received at least 1 year of DMTs (median 2 years) compared with $52 \%$ of the whole cohort of patients with MS $\left(\chi^{2}(1)=6.3, p=0.01\right)$.

As per place of residence, $1.1 \%$ of patients with MS with asthma lived on a farm, $19.5 \%$ lived in a small village, $42.5 \%$ lived in a small town, $25.3 \%$ lived in a 
Table 1 General demographic and clinical characteristics of the cohort

\begin{tabular}{|c|c|c|c|}
\hline & Total $(n=680)$ & With asthma $(n=88)$ & Without asthma $(n=592)$ \\
\hline Age (mean (SD)) & $53( \pm 11.5)$ & $48( \pm 11)$ & $53( \pm 11.2)$ \\
\hline Female \% & 66.67 & 76 & 70 \\
\hline Asthma \% & 12.94 & - & - \\
\hline \multicolumn{4}{|l|}{ Smoking \% } \\
\hline Ever-smoked & 62 & 64 & 62 \\
\hline Regularly smoked & 51 & 48 & 51 \\
\hline Father smoked & 60 & 55 & 61 \\
\hline Mother smoked & 38 & 37 & 38 \\
\hline EDSS (median (IQR)) & 5.5 (3 to 6.5$)$ & $4(3$ to 6.5$)$ & 5.5 (3 to 6.5$)$ \\
\hline MSIS-29 (median (IQR)) & 85 (60 to 106$)$ & 84 (59 to 108$)$ & 85 (60 to 106$)$ \\
\hline Psychological scale & 23 (16 to 31$)$ & 27 (17 to 34$)$ & 23 (16 to 31$)$ \\
\hline Physical scale & $62(41$ to 76$)$ & 60 (42 to 77$)$ & $62(41$ to 76$)$ \\
\hline DMT ( $\geq 1$-year) (\%) & 53 & 67 & 51 \\
\hline MS duration (median (IQR)) & $17(11$ to 26$)$ & $16(12$ to 24$)$ & $18(11$ to 27$)$ \\
\hline \multicolumn{4}{|l|}{ Disease course (\%) } \\
\hline Relapsing remitting & 57 & 72 & 54 \\
\hline Secondary progressive & 34 & 24 & 35 \\
\hline Primary progressive & 9 & 3 & 10 \\
\hline Age at the onset of MS (median (IQR)) & 33 (26 to 41$)$ & 30 (23 to 37$)$ & 33 (26 to 41$)$ \\
\hline
\end{tabular}

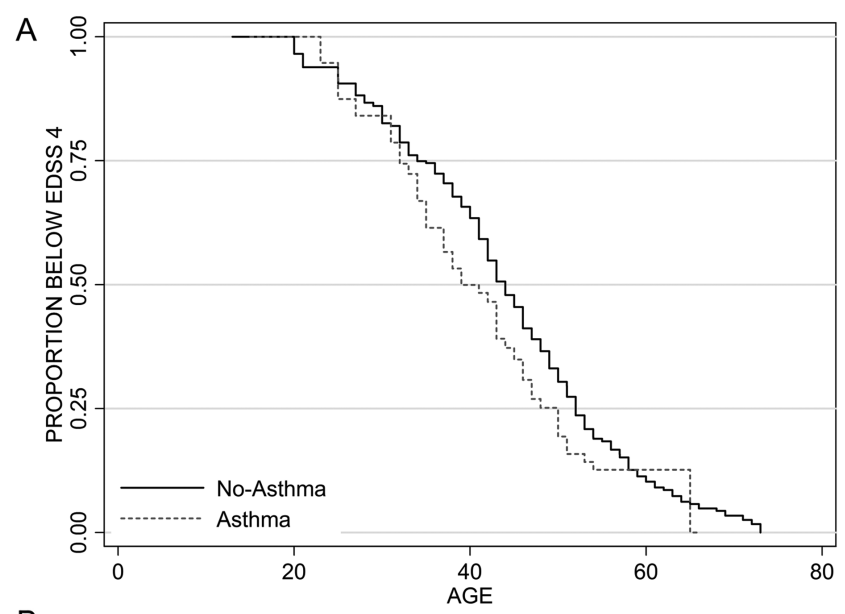

B

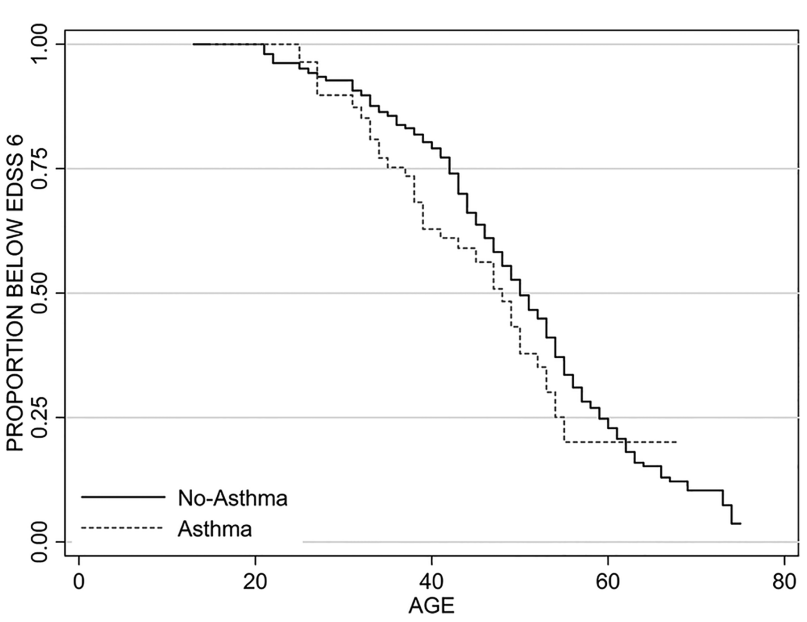

Figure 1 Kaplan-Meier graph showing A, time to expanded disability status scale (EDSS) score 4.0, B, time to EDSS score 6.0 by patients' asthma status. suburb of a city and $11.5 \%$ lived in an inner city when they were under the age of 5 years. For patients with MS without asthma this was $4.5 \%, 24.9 \%, 32.1 \%, 31.5 \%$ and $7 \%$, respectively $\left(\chi^{2}(4)=8.37, \mathrm{p}=0.08\right)$.

\section{PRESENCE OF ASTHMA AND MS DISABILITY \\ Time to EDSS score milestones 4.0 and $\mathbf{6 . 0}$}

Data needed to estimate the time to EDSS score 4.0 were available in $85 \%(\mathrm{n}=581)$ of the patients and time to EDSS score 6.0 in $90 \% \quad(n=612)$ of the patients. The proportion of missing data was not significantly different between asthma and non-asthma groups. Total follow-up time was 8347 and 9088 person-years for EDSS 4.0 and for EDSS 6.0, respectively. After controlling for sex, age at the onset of MS, disease initial clinical course, patient's smoking status at the time of disease onset and exposure to DMTs, patients with MS with asthma were not at higher risk of reaching EDSS score 4.0 or 6.0 compared to those without asthma: HRs of 1.29 (95\% CI 0.93 to $1.77, \mathrm{p}=0.11$ ) and 1.33 (95\% CI 0.93 to 1.89 , $\mathrm{p}=0.11$ ), respectively (figure $1 \mathrm{~A}, \mathrm{~B}$ ).

The unadjusted models showed almost similar results for both EDSS 4.0 and EDSS 6.0. The magnitude was in the same line for both EDSS scores, when the models were adjusted for age, sex, number of pack years of cigarettes (0-1 and more than 1 pack), DMT and MS course (table 2).

\section{The physical and psychological scales (MSIS-29)}

We did not observe any significant association between having asthma and overall MSIS-29 score (coefficient: $0.67,95 \% \mathrm{CI}-10.47$ to $11.83, \mathrm{p}=0.9)$ and MSIS-29 physical scale (coefficient: $0.41,95 \%$ CI -7.56 to 8.39 , 
Table 2 Risk of asthma among the cohort with MS

\begin{tabular}{|c|c|c|c|c|}
\hline & Crude HR $(95 \% \mathrm{Cl})^{\star}$ & p Value & Adjusted HR (95\% Cl)† & p Value \\
\hline \multicolumn{5}{|c|}{ Time to EDSS score 4.0 ( $n=605)$} \\
\hline \multicolumn{5}{|l|}{ Asthma } \\
\hline No & - & & - & \\
\hline Yes & 1.27 (0.93 to 1.74$)$ & 0.12 & 1.29 (0.93 to 1.77$)$ & 0.11 \\
\hline \multicolumn{5}{|l|}{ Gender } \\
\hline Male & - & & - & \\
\hline Female & 0.78 (0.62 to 0.98$)$ & 0.03 & 0.84 (0.66 to 1.08$)$ & 0.18 \\
\hline \multicolumn{5}{|c|}{ Pack-years smoked from MS onset to EDSS 4.0} \\
\hline$<1$ & - & & - & \\
\hline$>1$ & $1.32(1.04$ to 1.67$)$ & 0.02 & 1.31 (1.03 to 1.67$)$ & 0.02 \\
\hline \multicolumn{5}{|l|}{$\mathrm{DMT} \geq 1$ year } \\
\hline No & - & & - & \\
\hline Yes & $1.25(1.00$ to 1.56$)$ & 0.04 & 1.36 (1.07 to 1.73$)$ & 0.01 \\
\hline \multicolumn{5}{|c|}{ Disease clinical course at onset } \\
\hline Relapsing onset & - & & - & \\
\hline Progressive onset & 1.85 (1.34 to 2.54$)$ & $<0.001$ & 2.29 (1.62 to 3.28$)$ & $<0.001$ \\
\hline \multicolumn{5}{|c|}{ Time to EDSS score $6.0(n=612)$} \\
\hline \multicolumn{5}{|l|}{ Asthma } \\
\hline No & - & & - & \\
\hline Yes & $1.33(0.93$ to 1.88$)$ & 0.10 & $1.33(0.93$ to 1.89$)$ & 0.11 \\
\hline \multicolumn{5}{|l|}{ Gender } \\
\hline Male & - & & - & \\
\hline Female & $0.74(0.58$ to 0.95$)$ & 0.02 & 0.79 (0.61 to 1.03$)$ & 0.09 \\
\hline \multicolumn{5}{|c|}{ Pack-years smoked from MS onset to EDSS 6.0} \\
\hline$<1$ & - & & - & \\
\hline$>1$ & $1.19(0.92$ to 1.55$)$ & 0.17 & $1.20(0.91$ to 1.56$)$ & 0.18 \\
\hline \multicolumn{5}{|l|}{ DMT $\geq 1$ year } \\
\hline No & - & & - & \\
\hline Yes & $1.27(1.00$ to 1.62$)$ & 0.04 & 1.35 (1.03 to 1.76$)$ & 0.02 \\
\hline \multicolumn{5}{|c|}{ Disease clinical course at onset } \\
\hline Relapsing onset & - & & - & \\
\hline Progressive onset & $1.58(1.12$ to 2.21$)$ & 0.008 & 1.92 (1.32 to 2.78$)$ & 0.001 \\
\hline
\end{tabular}

$\mathrm{p}=0.91$ ). However, patients with asthma had significantly higher level of psychological impairment as measured by MSIS-29 psychological scale (coefficient: 4.57, 95\% CI 1.23 to $7.90, \mathrm{p}=0.007$; figure 2 ).

\section{DISCUSSION}

Here, we evaluated the association between comorbid asthma and the clinical course of MS. As asthma is a relatively common disease and is increasing in prevalence, affecting almost one in five people in countries, such as $\mathrm{UK}^{16}{ }^{16}$ it seemed important to evaluate the extent of influence of each condition on the other's clinical course. ${ }^{17}$ In the current work, we employed two widely used disability outcomes in MS, EDSS and MSIS-29. We could not find a pronounced association between comorbid asthma and MS physical disability although there was a trend toward a higher psychological impairment in those patients with MS who also had asthma. We found tobacco smoking, male gender and progressive onset to be associated with shorter time to EDSS score milestones 4.0 and 6.0. These findings are in line with the previously published data. ${ }^{18}$ We also found a higher risk of reaching the two disability milestones in those patients who were exposed to DMTs. This paradoxical finding may be related to the effect of the timing of introduction of DMT in the UK on this clinical cohort.

Our finding of the prevalence of asthma in patients with MS is compatible with the results from the meta-analysis by Monteiro et al. ${ }^{4}$ However, it is different from a previous survey in our centre and the study by Ponsonby $e t a l^{8}$ that showed a significantly higher prevalence of asthma in patients with $\mathrm{MS} ;{ }^{1}$ the results from a survey in Wales showed reduced prevalence of asthma in MS cases. ${ }^{3}$ The exact reason for this discrepancy needs further investigation. The earlier study in our centre ${ }^{1}$ showed a higher proportion of people with asthma and atopy in the MS population compared to this study. There are several possible explanations for this. First, the control population used in the previous work was based on the literature and second, comparisons in the 


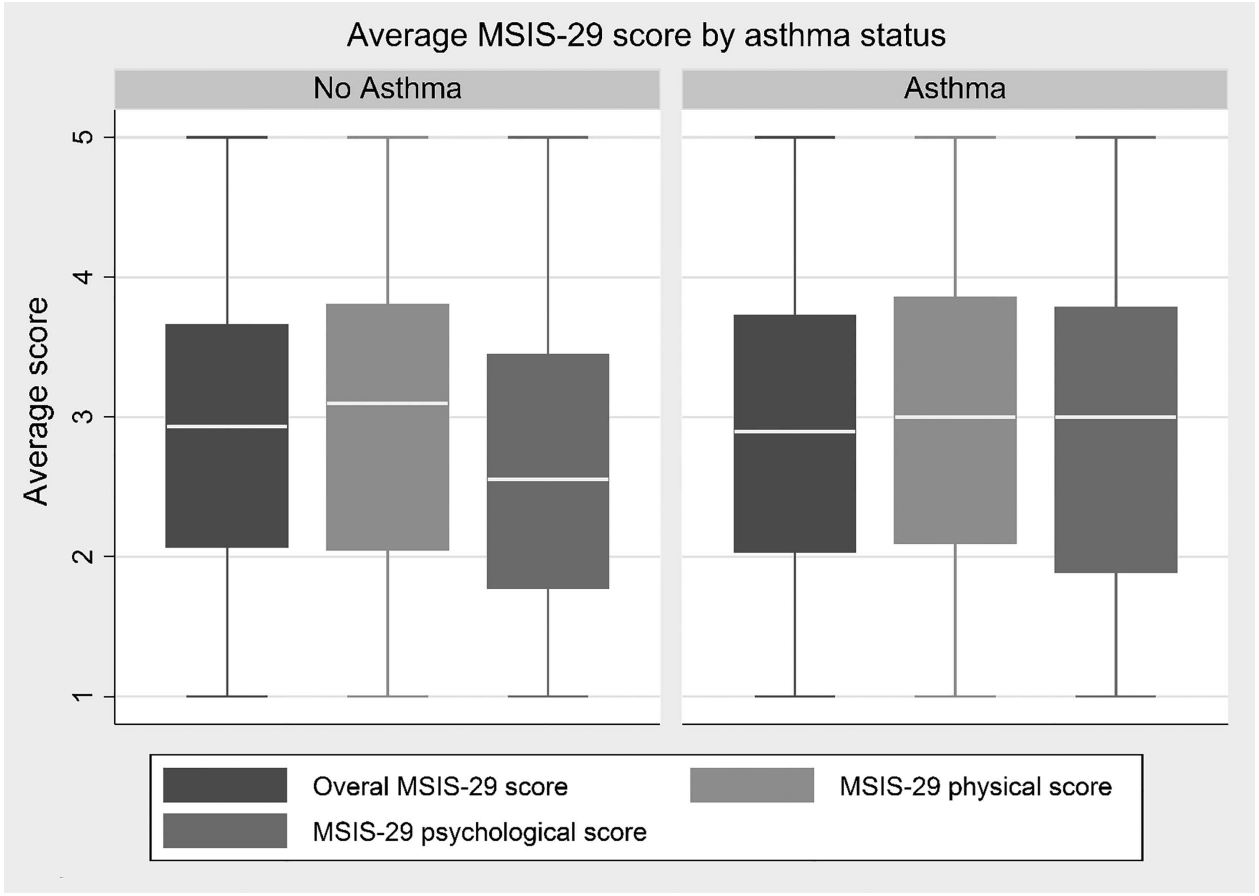

Figure 2 A box and whisker diagram illustrate median and IQR of mean overall Multiple Sclerosis Impact Scale 29 (MSIS-29), Physical MSIS-29 and Psychological scores.

previous work were based on prevalence in the whole group rather than those prevalent in age and sex stratified groups. Another possibility for these different results is that the criteria used in the earlier study were mainly based on current asthma and did not employ the comprehensive questionnaire used in this study. As shown here, when compared to controls without MS, patients with asthma with MS had lower recent attack rates (during the past 12 months) and only $45 \%$ were receiving treatment for their asthma. Hence, use of medication for asthma in patients with MS may be lower than controls which may subsequently influence the prevalence rate if prescription of a medication for asthma was used as an identifier for asthma cases. In addition, use of DMTs and steroids in patients with MS should also be considered as these drugs may modify asthma symptoms. 1920

Patients with MS are, in general, at higher risk of other immune-mediated disease ${ }^{7}$ however, asthma and rheumatoid arthritis has been reported to be inversely associated with MS. ${ }^{7} 21{ }^{3}$ Most reported risk factors common to both worsening of MS and of asthma are stress, tobacco, having a family member with asthma (6 times higher), ${ }^{22}$ MS (2 times higher), ${ }^{23}$ and viral infections. ${ }^{8}$ Some of these risk factors have probably influenced the risk of MS when the subjects were suffering from asthma. ${ }^{8}$

Conversely, those factors which lower the risk for MS relapses but increase asthma attacks are pregnancy, level of physical activity and age of onset. In general, especially physical activity is lowered in MS and this can delay the risk of asthma relapses and decrease the asthma diagnosis in patients with MS.

Generally around the age of 20 , asthma is reported to be equally distributed between males and females; however, in our study, the sex ratio was constantly in favour of females. This could suggest that female hormones are contributing factors to the increased risk of developing asthma at a higher age. ${ }^{24}$

Strengths of this study include the opportunity to examine both asthma and MS in a well-established cohort of patients with MS with routine clinical followups and detailed information on exposure. We had enough power to report the association between comorbid asthma and the relevant indicators of the course of MS. Further, this study used the self-reported MSIS-29, which is a responsive physical and psychological scale. ${ }^{25}$

Our study has some limitations. First, the asthma in our study is self-reported (although this needed to be confirmed by a doctor) and our analysis is based on only 88 cases of asthma in 680 patients with MS. Hence, our study could not be considered to be definitive. Second, the relatively old age in our cohort (mean age 52), which is typical for MS cohorts, may influence prevalence of asthma as asthma prevalence tends to decrease with age, particularly among smokers who tend to be diagnosed with chronic obstructive pulmonary disease (COPD) rather than asthma. ${ }^{26} 27$ In addition, with the response rate of $54 \%$, a potential selection bias may result from the proportion of non-responders among the MS cohort. 
There has been extensive speculation regarding the association of autoimmune and allergic diseases. The initial hypothesis of Th1/Th2 dichotomy postulated a deviation of the immune system towards a primarily Th1 (autoimmune) or Th2 (allergic) response, as demonstrated by the tendency towards one or the other type of disease in patient groups. ${ }^{3}{ }^{28}$ However, the discovery of Th17 and T regulatory (Treg) cells supports a common pathway of disordered reactivity to self or environmental factors, and there is evidence for Th17 and Treg dysregulation in a wide range of autoimmune and allergic disorders, including $\mathrm{MS}^{29}$ and asthma. ${ }^{30} 31$

Interestingly, our study shows that while the presence of coexisting asthma has no substantial impact on the clinical features of MS, the coexistence of MS may make asthma milder. In addition, the majority of the patients with MS with asthma (84\%) developed asthma before MS onset. This is compatible with the concept that the default immune response is predominantly Th2 (as in asthma) and in our population, most likely to precede the MS-triggering immune response. ${ }^{32}$ Such a response would then be disturbed and mitigated when a strong Th1/Th17, that characterises MS, emerges despite the extant Th2 default background. ${ }^{33}$ When considering the results of this study, we need to take into account the relatively low number of subjects with coexisting MS and asthma (88 out of 680 ).

\section{CONCLUSIONS}

Asthma is a prevalent condition among patients with MS and it may contribute to the psychological impairment in MS. Although we did not observe a significant association between comorbid asthma and physical disability in MS, it seems that the two conditions influence one another. The shifting toward Th1, a suggested proinflammatory process in MS, may play a role in the lower risk of asthma after MS.

Contributors AM was involved in study concept and design, acquisition, analysis and interpretation of the data and critical revision of the manuscript for important intellectual content. CSC was involved in developing the study concept and design, critical revision of the manuscript for important intellectual content. CSC supervised the study and was also involved in acquisition of data. LJE and HR were involved in interpretation of the data and critical revision of the manuscript for important intellectual content. CRT was involved in data analysis, interpretation of the data, design of the study and critical revision of the manuscript for important intellectual content.

Funding This study was funded by the University of Nottingham.

Competing interests AM, CRT, HR and LJE report no disclosures. CSC has received research support, support for travel to scientific meetings, consultancy and speaker honoraria from Biogen Idec, Bayer-Schering, Centocor, GW Pharmaceuticals, Merck-Serono, Morphosys and Teva Pharmaceuticals.

Ethics approval National Research Ethics Service East Midlands Ethics Committee Derby-1.

Provenance and peer review Not commissioned; externally peer reviewed.

Data sharing statement No additional data are available.

Open Access This is an Open Access article distributed in accordance with the Creative Commons Attribution Non Commercial (CC BY-NC 4.0) license, which permits others to distribute, remix, adapt, build upon this work noncommercially, and license their derivative works on different terms, provided the original work is properly cited and the use is non-commercial. See: http:// creativecommons.org/licenses/by-nc/4.0/

\section{REFERENCES}

1. Edwards LJ, Constantinescu CS. A prospective study of conditions associated with multiple sclerosis in a cohort of 658 consecutive outpatients attending a multiple sclerosis clinic. Mult Scler 2004;10:575-81.

2. Bergamaschi R, Villani S, Crabbio M, et al. Inverse relationship between multiple sclerosis and allergic respiratory diseases. Neurol Sci 2009;30:115-18.

3. Tremlett HL, Evans J, Wiles CM, et al. Asthma and multiple sclerosis: an inverse association in a case-control general practice population. QJM 2002;95:753-6.

4. Monteiro L, Souza-Machado A, Menezes C, et al. Association between allergies and multiple sclerosis: a systematic review and meta-analysis. Acta Neurol Scand 2011;123:1-7.

5. Broadley SA, Deans J, Sawcer SJ, et al. Autoimmune disease in first-degree relatives of patients with multiple sclerosis. A UK survey. Brain 2000;123(Pt 6):1102-11.

6. Langer-Gould A, Albers KB, Van Den Eeden SK, et al. Autoimmune diseases prior to the diagnosis of multiple sclerosis: a population-based case-control study. Mult Scler 2010;16:855-61.

7. Roshanisefat $\mathrm{H}$, Bahmanyar S, Hillert J, et al. Shared genetic factors may not explain the raised risk of comorbid inflammatory diseases in multiple sclerosis. Mult Scler 2012;18:1430-6.

8. Ponsonby AL, Dwyer T, van der Mei I, et al. Asthma onset prior to multiple sclerosis and the contribution of sibling exposure in early life. Clin Exp Immunol 2006;146:463-70.

9. Manouchehrinia A, Weston M, Tench CR, et al. Tobacco smoking and excess mortality in multiple sclerosis: a cohort study. J Neurol Neurosurg Psychiatry 2014;85:1091-5.

10. Manouchehrinia A, Tench CR, Maxted J, et al. Tobacco smoking and disability progression in multiple sclerosis: United Kingdom cohort study. Brain 2013;136(Pt 7):2298-304.

11. Centre THaSCl. Health survey for England-2010, respiratory health [NS]. National Statistics, 2011.

12. Burney PG, Luczynska C, Chinn S, et al. The European Community Respiratory Health Survey. Eur Respir J 1994;7:954-60.

13. Poser CM, Paty DW, Scheinberg $L$, et al. New diagnostic criteria for multiple sclerosis: guidelines for research protocols. Ann Neurol 1983;13:227-31.

14. McDonald WI, Compston A, Edan G, et al. Recommended diagnostic criteria for multiple sclerosis: guidelines from the International Panel on the diagnosis of multiple sclerosis. Ann Neurol 2001;50:121-7.

15. Kurtzke JF. Rating neurologic impairment in multiple sclerosis: an expanded disability status scale (EDSS). Neurology 1983;33:1444-52

16. Simpson CR, Sheikh A. Trends in the epidemiology of asthma in England: a national study of 333,294 patients. J $R$ Soc Med 2010;103:98-106

17. Marrie RA, Horwitz RI. Emerging effects of comorbidities on multiple sclerosis. Lancet Neurol 2010;9:820-8.

18. Tremlett $H$, Zhao $Y$, Rieckmann $P$, et al. New perspectives in the natural history of multiple sclerosis. Neurology 2010;74:2004-15.

19. Djukanović R, Harrison T, Johnston SL, et al. The effect of inhaled IFN- $\beta$ on worsening of asthma symptoms caused by viral infections. A randomized trial. Am J Respir Crit Care Med 2014;190:145-54.

20. Cakebread JA, Xu Y, Grainge C, et al. Exogenous IFN-beta has antiviral and anti-inflammatory properties in primary bronchial epithelial cells from asthmatic subjects exposed to rhinovirus. J Allergy Clin Immunol 2011;127:1148-54 e9.

21. Nielsen NM, Frisch M, Rostgaard K, et al. Autoimmune diseases in patients with multiple sclerosis and their first-degree relatives: a nationwide cohort study in Denmark. Mult Scler 2008;14:823-9.

22. Liu T, Valdez R, Yoon PW, et al. The association between family history of asthma and the prevalence of asthma among US adults: National Health and Nutrition Examination Survey, 1999-2004. Genet Med 2009;11:323-8.

23. O'Gorman C, Lin R, Stankovich J, et al. Modelling genetic susceptibility to multiple sclerosis with family data. Neuroepidemiology 2013;40:1-12.

24. Dratva J. Use of oestrogen only hormone replacement therapy associated with increased risk of asthma onset in postmenopausal women. Evid Based Med 2010;15:190-1. 
25. Hobart JC, Riazi A, Lamping DL, et al. How responsive is the Multiple Sclerosis Impact Scale (MSIS-29)? A comparison with some other self report scales. J Neurol Neurosurg Psychiatry 2005;76:1539-43.

26. Tinkelman DG, Price DB, Nordyke RJ, et al. Misdiagnosis of COPD and asthma in primary care patients 40 years of age and over. $J$ Asthma 2006;43:75-80.

27. Gibson PG, Simpson JL. The overlap syndrome of asthma and COPD: what are its features and how important is it? Thorax 2009;64:728-35.

28. Evans J, Rogers C, Wiles CM, et al. General practitioners' prescribing data for multiple sclerosis patients indicates a link with asthma. Br J Gen Pract 2000;50:323-4.
29. Edwards LJ, Sharrack B, Ismail A, et al. Central inflammation versus peripheral regulation in multiple sclerosis. J Neurol 2011;258:1518-27.

30. Doe C, Bafadhel M, Siddiqui S, et al. Expression of the T helper 17-associated cytokines IL-17A and IL-17F in asthma and COPD. Chest 2010;138:1140-7.

31. Shi YH, Shi GC, Wan HY, et al. Coexistence of Th1/Th2 and Th17/ Treg imbalances in patients with allergic asthma. Chin Med J (Engl) 2011;124:1951-6.

32. Adkins B. Development of neonatal Th1/Th2 function. Int Rev Immunol 2000;19:157-71.

33. Edwards LJ, Robins RA, Constantinescu CS. Th17/Th1 phenotype in demyelinating disease. Cytokine 2010;50:19-23. 